\title{
Abdominal Pain in Children and Adolescents with Autism Spectrum Disorder: a Systematic Review
}

\author{
Julia Lanyi $^{1} \cdot$ Christopher Flynn $^{1} \cdot$ Arlene Mannion $^{1} \cdot$ Leanne Maher $^{1} \cdot$ Katie Naughton $^{1} \cdot$ Geraldine Leader $^{1}$
}

Received: 4 July 2020 / Accepted: 17 March 2021 / Published online: 11 May 2021

(C) The Author(s) 2021

\begin{abstract}
The aim of this study was to review the existing literature on abdominal pain in children and adolescents with autism spectrum disorder. Systematic search of four databases (PsycINFO, ERIC, PubMed, MEDLINE) identified 13 studies that met the inclusion criteria. Articles were analyzed for common themes, including the prevalence of abdominal pain and gastrointestinal (GI) symptoms, associations between abdominal pain/GI symptoms and behavioral and emotional concerns, associations between abdominal pain/GI symptoms, and other comorbid disorders and treatment options based on gut bacteria, diet, and probiotics. Reasons for varying prevalence rates, persistence of symptoms over time, comorbidities, and different treatment options are discussed. Clinical implications and recommendations for future research are also discussed.
\end{abstract}

Keywords Autism spectrum disorder · Abdominal pain · Gastrointestinal symptoms · Comorbidity $\cdot$ Children · Adolescent

\section{Introduction}

Autism spectrum disorder (ASD) is a neurodevelopmental disorder characterized by impairments in social communication as well as restricted, repetitive behavior, interests, or activities (American Psychiatric Association, 2013). The estimated prevalence of ASD is one in 54, based on the recent published findings of the Autism and Developmental Disabilities Monitoring Network (Maenner et al., 2020). Prevalence rates of ASD are 4.3 times higher for boys (29.7 per 1000), compared to girls (6.9 per 1000) (Maenner et al., 2020).

A number of conditions are comorbid with ASD and other developmental disorders including attention-deficit/hyperactivity disorder ( $\mathrm{AD} / \mathrm{HD})$, epilepsy,sleep problems, challenging behavior, and toileting problems (Devlin et al., 2008; Foody et al. 2014; Leader et al., 2018; Leader \& Mannion, 2016a; Mannion \& Leader, 2014a, 2014b; Newman et al., 2015). Among the most common medical conditions comorbid with ASD are gastrointestinal (GI) symptoms (Leader \&

Geraldine Leader

geraldine.leader@nuigalway.ie

1 Irish Centre for Autism and Neurodevelopmental Research (ICAN), School of Psychology, National University of Ireland,

Galway, Ireland
Mannion, 2016b; Tye et al., 2019) and recent research has reported that $82.4 \%$ of children and adolescents with ASD experience at least one GI symptom (Leader et al., 2020). The most common GI symptoms reported in individuals with ASD include abdominal pain, diarrhea, acid reflux, bloating, nausea, and constipation (Mannion \& Leader, 2016; Mannion \& Leader, 2013). Researchers have found that children with ASD are at an almost eight times greater risk of experiencing one or more chronic GI symptoms compared to typically developing children (Chaidez et al., 2014). Among those with an ASD diagnosis, GI symptoms can be particularly challenging to recognize, as some individuals are non-verbal and many have impaired communication, therefore expressing pain or discomfort may be more difficult (Buie et al., 2010).

Identifying abdominal pain and GI symptoms in individuals with ASD is imperative. There is growing evidence, however, suggesting that abdominal pain and GI symptoms may be linked to behavioral and mental health problems (Buie et al., 2013; Mazurek et al., 2012; Neuhaus et al., 2018). If abdominal pain and GI symptoms are not diagnosed and treated, this may lead to an increase in challenging behaviors. Subsequently, the management of these behaviors often warrants the administration of psychotropic medication which has negative side effects (Cvejic et al., 2018). The presence and severity of GI symptoms are an important aspect to be assessed in children with ASD, especially when evaluating behavioral and mental health concerns for this population. 
The treatment of GI symptoms may be an important factor in alleviating mental health concerns in children and adolescents with ASD (Neuhaus et al., 2018).

Neuhaus et al. (2018) studied the link between GI and psychiatric symptoms in 2756 children and adolescents with ASD using parent-reported questionnaires and interviews. Their findings revealed that GI symptoms accounted for a unique variance in internalizing, externalizing, and self-injurious behavior. A growing number of studies have been published regarding prevalence rates and etiology of GI symptoms. Less research exists, however, specifically on the origin and characteristics of abdominal pain in ASD. Diet is one possible cause of abdominal pain and GI symptoms (Gorrindo et al., 2012). A report focusing on GI symptoms in ASD concluded that some individuals with ASD may benefit from dietary interventions, such as avoidance of lactose, gluten, or casein (Buie et al., 2010). A systematic review investigating the relationship between ASD and a gluten-free diet has reported that a variety of symptoms may be present with gluten sensitivity (Mulloy et al., 2010). According to Buie (2013), food allergies causing gut inflammation may induce pain and other GI symptoms in individuals with ASD and this subgroup may benefit from dietary interventions. Based on 12,984 stool-pattern analysis, Sandhu et al. (2009) identified that from 30 months of age, there is an increase in stool frequency in children with ASD and that this may be attributed to differences in diet.

Feeding problems have also been identified as a cause of GI symptoms (Leader et al., 2020; Levy et al., 2007). Food selectivity and refusal are commonly reported in children with ASD (Schreck et al., 2004), which have an impact on the ability to feed effectively and receive adequate nutrition (Erickson et al., 2005). Levy et al. (2007) revealed from 62 diet diaries of children with ASD that feeding difficulties such as selectivity and poor oral intake may aggravate GI symptoms, i.e., constipation. Recent research on feeding problems in relation to GI symptoms, challenging behavior, and sensory issues in children and adolescents with ASD found that those with a feeding problem experienced significantly more GI symptoms, compared to those without a feeding problem (Leader et al., 2020).

Stress, anxiety, and behavioral problems have also been suggested as a cause of abdominal pain and GI symptoms in children with ASD (Chaidez et al., 2014; Ferguson et al., 2016; Mazefsky et al., 2014). Ferguson et al. (2016) examined the relationship between stress and GI symptoms in 120 children and adolescents with ASD by measuring salivary cortisol, and results of this study revealed a significant association between GI symptoms and post-stress cortisol levels. These findings suggest that individuals with ASD who experience GI symptoms may have an increased response to stress.

\section{Current Study}

Limitations to previous studies include that most findings are based solely on parent report rather than medical evaluation of GI symptoms. Furthermore, there is potential variation of data due to lack of standardized definitions for GI symptoms. The current study addresses previous limitations by outlining assessment tools used for GI symptoms and abdominal pain and reviews and synthetizes results from multiple sources. The current study aimed to review the existing literature in a systematic manner focusing on publications on abdominal pain in children and adolescents with ASD. The current study aimed to address the following research questions: (i) What prevalence rates are reported for abdominal pain and GI symptoms in children and adolescents with ASD? (ii) What are the factors and comorbidities associated with abdominal pain? and (iii) What are the available treatments options? The current review sought to synthetize the findings of the included studies based on these research questions and to provide a clearer understanding on the knowledge available on abdominal pain in ASD.

\section{Method}

\section{Search Procedures}

Multiple online research databases including PsycINFO, ERIC, PubMed and MEDLINE were searched to identify potential studies on abdominal pain in children and adolescents with ASD. No lower year limit was set, and articles were included up to the date in which the search was completed (i.e., November 2018 to February 2019). The following search words were used with asterisks and Boolean operators for each database: "Autism*" or "ASD" or "ASD Spectrum Disorder" and "Pain*" or "Ache*" or "Cramp*" or "Migraine" in combination with "Abdomen*" or "stomach" or "Abdominal Pain" and "Child*" or "Adolescent*" or "Pediatric*" or "Paediatric*." The search procedure utilized the Preferred Reporting Items for Systematic Reviews and Meta-Analysis (PRISMA) guidelines (Moher et al., 2010).

\section{Inclusion and Exclusion Criteria}

The authors reviewed titles and abstracts from the results of keyword searches in all databases and determined from the search results whether articles were relevant to the research questions. Search results were required to meet preestablished criteria in order to be included within the current review. Articles were required to be peer-reviewed and written in English. Participants were required to be children or adolescents aged between 0 and 18 years, with a diagnosis of ASD. Articles were included if they used at least one measure 
specifically for abdominal pain (either as a subscale of a GI scale or as a sole measure). Both single-subject and groupdesign research were included.

\section{Data Extraction}

Studies that met the initial inclusion criteria underwent further analyses to extract data pertaining to the research aims of this paper. Data extraction included descriptive factors such as the method of data collection, recruitment setting, sample size, age and gender, abdominal pain assessment tools, co-occurring disorders, intervention, results and summary of findings. Two authors reviewed each article and extracted data separately from each other, after which an inter-observer agreement (IOA) was calculated to ensure reliability of outcomes. In 93\% of cases, both authors extracted the same information, while in the remaining $7 \%$ of cases, a discussion resolved the disagreement. Articles were then analyzed based on the three main research questions outlined above, and the following categories were identified: (i) prevalence of abdominal pain and GI symptoms, (ii) associations between abdominal pain/GI symptoms and behavioral and emotional concerns, (iii) associations between abdominal pain/GI symptoms and other comorbid disorders, and (iv) treatment options based on gut bacteria, diet, and probiotics. Categories were directly linked to research questions; however, modifications were made based on frequency of results (i.e., behavioral/emotional concerns formed a separate category due to high volume of findings and treatment options specified based on findings).

\section{Reliability and Inter-observer Agreement}

Reliability of the search outcomes was assessed using IOA to ensure that the methodology of the review was replicable. Two authors carried out searches in the four databases independently and screened the titles and abstracts of articles for inclusion and exclusion. Articles were then matched to each other and identical ones counted as agreement and included. Articles without a match were counted as disagreement. When there was a disagreement on an article, authors examined the study based on the inclusion criteria and reached agreement on whether to keep the article in the study or not. Details of the search terms used and IOA for each database are described in Table 1 and Table 2.

\section{Results}

\section{Flow Diagram}

Following the database searches, 13 articles were identified and included in the current review. Figure 1 presents the process of inclusion and exclusion of records during the search procedure.

\section{Summary of Study Findings}

All 13 articles were reviewed by their content and analyzed for common themes. First, a summary table is presented with the findings, and then all four themes identified are discussed in detail in terms of the main findings. Table 3 summarizes the findings of the selected studies.

\section{Prevalence of Abdominal Pain and GI Symptoms}

The prevalence of abdominal pain and GI symptoms was reported in eight articles included in this study. Mazefsky et al. (2014) reported that from the sample of 95 children with high-functioning ASD, $61 \%$ of participants had at least one GI symptom. Forty one percent of participants reported abdominal pain, which was the most commonly reported GI symptom according to their findings. Results showed that $28.4 \%$ of participants had one GI symptom, $22.1 \%$ presented with two, and $10.6 \%$ had three or more GI symptoms. There was a significant difference between the group with and without GI symptoms in relation to age and gender. GI symptoms were associated with females and a younger age.

Molloy and Manning-Courtney (2003) reported that out of the 137 study participants, 33 children (24\%) suffered from at least one GI symptom. A total of $2.1 \%$ of participants reported abdominal pain, and chronic diarrhea (12.4\%) was the most common GI symptom. A study conducted by Gondalia et al. (2012) found that out of 104 participants, 14\% experienced abdominal pain and 55\% had at least one GI dysfunction.

Furthermore, Chaidez et al. (2014) conducted a study which consisted of 960 children with ASD, developmental delays (DD), and typically developing (TD) peers. Their findings reveal that parents of children with ASD reported the highest percentage of abdominal pain $(5.1 \%)$, followed by children with DD (3.9\%) and TD participants (1.6\%) according to parental reports. Results indicate that children with ASD are six to eight times more likely to experience other GI symptoms, such as diarrhea, constipation, bloating, and food sensitivity compared to a TD group.

Similar results were revealed in a study by Chandler et al. (2013), and their study consisted of 295 children with ASD, special education needs (SEN), and TD peers. A total of $21.7 \%$ of participants with ASD reported previous experiences of abdominal pain, whereas the SEN group reported $6.4 \%$. Past experiences of abdominal pain were correlated to current abdominal pain in the ASD group, but not in the other two groups.

A longitudinal study by Mazurek et al. (2014) investigated abdominal pain in participants with ASD over 1 year. Their findings reveal that at baseline $25.8 \%$ of participants experienced chronic abdominal pain, and after the 1-year follow-up, they 
Table 1 Search terms used

\begin{tabular}{|c|c|c|c|c|c|c|}
\hline Keyword & & Keyword & & Keyword & & Keyword \\
\hline Autism & AND & Pain & AND & Abdomen & AND & Child \\
\hline OR & & OR & & OR & & OR \\
\hline ASD & & Ache & & Stomach & & Adolescent \\
\hline OR & & OR & & OR & & OR \\
\hline \multirow[t]{3}{*}{ ASD Spectrum Disorder } & & Cramp & & Abdominal pain & & Pediatric \\
\hline & & OR & & & & OR \\
\hline & & Migraine & & & & Paediatric \\
\hline
\end{tabular}

found that this pain persisted in $86.4 \%$ of the participants. This study coincides with research conducted by Mannion and Leader (2016) as they investigated abdominal pain in children with ASD throughout a 2-year longitudinal study. Their findings reveal that $48.3 \%$ of participants with ASD experienced abdominal pain at baseline and $72.4 \%$ of those children persisted with this pain at the 2-year follow-up. In addition to those findings, Mannion and Leader (2016) found that GI symptoms persisted in $84.4 \%$ of cases, whereby diarrhea and constipation were the most common reported GI symptoms.

Sandhu et al. (2009) studied stool patterns and GI symptoms of 12,984 children with and without a diagnosis of ASD at five different timepoints in the first 3.5 years of life. Results of their study found no significant differences between the frequencies of abdominal pain reported in children with ASD in comparison to the TD group. Furthermore, there was no significant difference observed in the prevalence of diarrhea, constipation, or stool color between the two groups.

\section{Associations Between Abdominal Pain/GI Symptoms and Behavioral and Emotional Concerns}

Four studies included in this review focused on abdominal pain and GI symptoms in children with ASD and their relation to emotional or behavioral concerns. Emotional/behavioral problems were operationally defined by variables measuring dysregulation of covert constructs, such as mood, often labelled as anxiety, depression, irritability, or affective problems or a deviation from socially appropriate overt behaviors, including, but not limited to self-injury, aggressive behavior, tantrum, hyperactivity, or defiant behavior.

Mazefsky et al. (2014) studied 95 children with highfunctioning ASD with and without GI symptoms and investigated the difference between the two groups in relation to emotional and behavioral concerns. Children with GI symptoms did not differ from those without in relation to adaptive behavior scores or the total internalizing and
Fig. 1 Flow diagram showing studies identified and included from the database searches

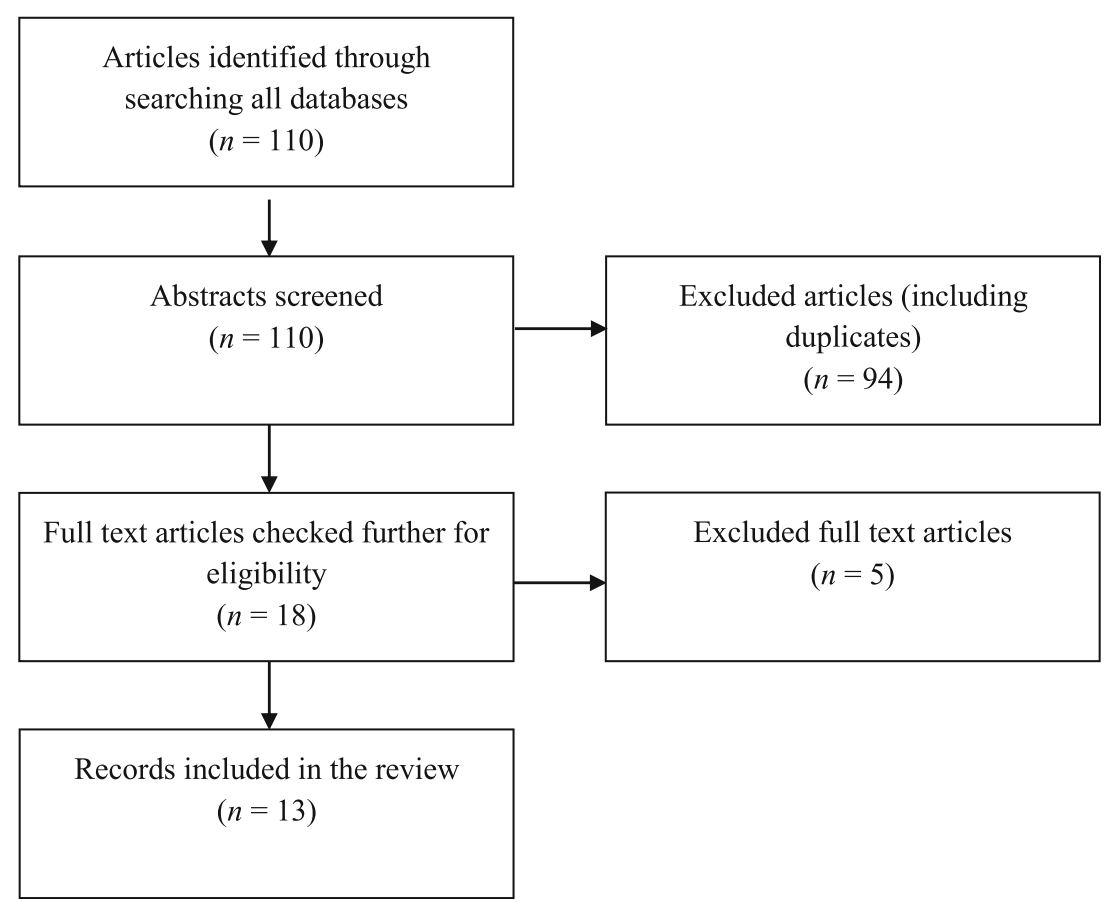


Table 2 Inter-observer agreement (IOA) for each database

\begin{tabular}{lll}
\hline Database & IOA & IOA after discussion \\
\hline PubMed & $77 \%$ & $100 \%$ \\
PsycINFO & $89 \%$ & $100 \%$ \\
MEDLINE & $94 \%$ & $100 \%$ \\
ERIC & $100 \%$ & $100 \%$ \\
Total IOA & $90 \%$ & \\
\hline
\end{tabular}

externalizing scores. However, children with GI symptoms scored significantly higher on the affective problems, somatic complaints, and somatic problems subscales of the Child Behavior Checklist (CBCL).

Fulceri et al. (2016) reported similar findings as they studied the difference between children with ASD and TD peers with or without GI symptoms. Findings suggested that GI symptoms are associated with more emotional and behavioral problems in participants with ASD. Participants with ASD had higher scores on the anxiety problems, somatic complaints, externalizing, and total problems subscales of the CBCL. Fulceri et al. (2016) discussed how GI symptoms could be a trigger for problem behaviors or may exacerbate them. Interestingly, the TD peer group did not show a significant difference between the groups with and without GI symptoms on any of the CBCL subscales.

Chaidez et al. (2014) studied the association between GI symptoms and behavioral problems using the Aberrant Behavior Checklist (ABC). Children with ASD and specific GI symptoms (abdominal pain, diarrhea, constipation) scored significantly higher on four out of five subscales of the $A B C$, specifically, irritability, social withdrawal, stereotypy, and hyperactivity in comparison to children without GI symptoms. Other frequent GI symptoms (pain on stooling, difficulty swallowing, and food sensitivity) were also associated with irritability, social withdrawal, and stereotypy in participants with ASD. Mazurek et al. (2014) conducted a longitudinal study with a sample of 2973 children with ASD. At baseline, it was found that participants with abdominal pain scored significantly higher on anxiety compared to the group without pain. In addition to this, anxiety did not predict abdominal pain at the follow-up timepoint.

\section{Associations Between Abdominal Pain/GI Symptoms and Other Comorbid Disorders}

The search procedure produced three articles related to $a b-$ dominal pain/GI symptoms and other comorbid disorders specifically sleep problems, social functioning, and sensory overresponsivity. Mazurek et al. (2014) found that in a sample of 2973 children with ASD, participants with abdominal pain scored significantly lower on sensory over-responsivity
(SOR) compared to the group without pain. The authors also assessed whether SOR or anxiety predicted the development of abdominal pain at the follow-up timepoint and found that only SOR was a predictor of abdominal pain.

Gorrindo et al. (2012) investigated the difference between TD children and participants with ASD and GI symptoms, as well as participants with ASD without GI symptoms in relation to social and language impairment. A significant difference was found in language skills as $30 \%$ of participants reported as non-verbal in the ASD group with GI symptoms compared to $6.7 \%$ in the ASD-only group. Social impairment was also significantly higher in the ASD group with GI symptoms compared to the two other groups.

Mannion and Leader (2016) studied comorbid psychology in 56 children and adolescents with ASD and found that $64.3 \%$ of participants who experienced GI symptoms also reported sleep problems. More specifically, Mannion and Leader (2016) found that $92.6 \%$ of children with abdominal pain experienced sleep problems, as well as $94.4 \%$ of participants with bloating, $88.5 \%$ with diarrhea, and $87.5 \%$ with constipation.

\section{Treatment Options Based on Gut Bacteria, Diet, and Probiotics}

Five studies from the articles included in this review focused on treatment options, or research questions linked to treatment. Kang et al. (2017) examined a treatment option for GI symptoms for 18 children with ASD, based on the gut microbiome. A small clinical trial was conducted to evaluate the effect of a 10 -week-long microbiota transfer therapy (MTT) on GI disturbances. Results showed an $82 \%$ decrease in GI symptoms after treatment, and this result was maintained at the 8 -week follow-up in $77 \%$ of the cases. A significant reduction was found in abdominal pain, constipation, and diarrhea from the GI symptoms after the MTT.

Gondalia et al. (2012) also studied the relationship of intestinal microbiota, GI symptoms, and ASD. Specifically, they examined the differences between the microbiota of TD children and their siblings diagnosed with ASD. Three groups were compared to each other in relation to intestinal microbiota, children with ASD, TD siblings, and participants with ASD and GI symptoms. Interestingly, no significant difference was found in the bacterial content of fecal samples between any of the three groups.

Grimaldi et al. (2018) published a study on treatment options for GI symptoms in ASD based on dietary intervention. Grimaldi et al. (2018) evaluated the impact of exclusion diets (gluten and casein-free) and a 6-week prebiotic treatment (Bimuno ${ }^{\circledR}$ galactooligosaccharide) in 30 participants with ASD on GI symptoms. Their finding based on the analysis of baseline dietary diaries showed that participants on exclusion diets reported significantly lower scores of abdominal 
Table 3 Summary of studies on abdominal pain in children and adolescence with ASD

\begin{tabular}{|c|c|c|c|c|c|c|}
\hline Study & Aim & $\begin{array}{l}\text { Sample } \\
\text { size }\end{array}$ & Age & $\begin{array}{l}\text { Abdominal pain } \\
\text { assessment tool }\end{array}$ & Intervention & Results \\
\hline Chaidez et al. (2014) & $\begin{array}{l}\text { To compare GI symptoms } \\
\text { between children with } \\
\text { ASD, typical development } \\
\text { (TD), and developmental } \\
\text { delay (DD) }\end{array}$ & $N=960$ & $\begin{array}{l}\text { 24-60 } \\
\text { months }\end{array}$ & $\begin{array}{l}\text { Parent reports open-ended } \\
\text { GI questions (Chaidez } \\
\text { et al., 2014) }\end{array}$ & N/A & $\begin{array}{l}\text { Parent report of at least one } \\
\text { frequent GI symptom was } \\
\text { significantly higher for } \\
\text { children with ASD and } \\
\text { children with DD, } \\
\text { compared to children with } \\
\text { TD }\end{array}$ \\
\hline Chandler et al. (2013) & $\begin{array}{l}\text { To study the difference } \\
\text { between parent-reported GI } \\
\text { symptoms in children with } \\
\text { ASD, special educational } \\
\text { needs (SEN), and TD }\end{array}$ & $N=295$ & $\begin{array}{r}10-14 \\
\text { years }\end{array}$ & $\begin{array}{l}\text { GI symptom } \\
\text { questionnaire } \\
\text { (Chandler et al., 2013) }\end{array}$ & N/A & $\begin{array}{l}46.5 \% \text { of participants with } \\
\text { ASD had at least one GI } \\
\text { symptom compared with } \\
21.8 \% \text { of TD and } 29.2 \% \\
\text { with SEN }\end{array}$ \\
\hline Fulceri et al. (2016) & $\begin{array}{l}\text { To investigate the prevalence of } \\
\text { GI symptoms in children } \\
\text { with ASD and their relation } \\
\text { to behavioral problems }\end{array}$ & $N=230$ & $\begin{array}{l}\text { Mean } \\
\text { age }= \\
3.8 \\
\text { years }\end{array}$ & $\begin{array}{l}\text { Child Behavior Checklist } \\
\text { Somatic Complaints } \\
\text { scale (Frigerio et al., } \\
\text { 2006) }\end{array}$ & N/A & $\begin{array}{l}\text { A significantly higher } \\
\text { percentage of GI symptoms } \\
\text { were found in the ASD } \\
\text { group }(37.4 \%) \text { versus TD } \\
(14.8 \%) \text {. Children with } \\
\text { ASD and GI symptoms had } \\
\text { higher levels of anxiety and } \\
\text { externalizing problems }\end{array}$ \\
\hline Gondalia et al. (2012) & $\begin{array}{l}\text { To compare the GI microbial } \\
\text { community in children with } \\
\text { ASD and their TD siblings }\end{array}$ & $N=104$ & $\begin{array}{l}2-12 \\
\text { years }\end{array}$ & $\begin{array}{l}\text { Parental questionnaire of } \\
\text { GI symptoms }\end{array}$ & N/A & $\begin{array}{l}\text { No clinically meaningful } \\
\text { difference in the fecal } \\
\text { microbial community } \\
\text { between the } 2 \text { groups }\end{array}$ \\
\hline Gorrindo et al. (2012) & $\begin{array}{l}\text { To compare parent-reported GI } \\
\text { symptoms with results of } \\
\text { medical evaluation and to } \\
\text { examine relation between } \\
\text { dietary habits, medication } \\
\text { and GI symptoms. }\end{array}$ & $N=121$ & $\begin{array}{l}5-17 \\
\text { years }\end{array}$ & $\begin{array}{l}\text { Questionnaire on } \\
\text { Paediatric } \\
\text { Gastrointestinal } \\
\text { Symptoms and medical } \\
\text { examination } \\
\text { (Drossman, 2006) }\end{array}$ & N/A & $\begin{array}{l}92 \% \text { agreement was found } \\
\text { between parent and } \\
\text { clinician report of GI } \\
\text { symptoms. }\end{array}$ \\
\hline Grimaldi et al. (2018) & $\begin{array}{l}\text { To study the impact of diet on } \\
\text { gut microbiota and the } \\
\text { modulating effect of } \\
\text { probiotics }\end{array}$ & $N=30$ & $\begin{array}{l}\text { 4-11 } \\
\text { years }\end{array}$ & $\begin{array}{l}\text { Questionnaires on GI } \\
\text { symptoms (Girmaldi } \\
\text { et al., 2018) }\end{array}$ & $\begin{array}{l}\text { Exclusion diet } \\
\text { group } 1 \\
\text { received } \\
\text { placebo, } \\
\text { group } 2 \\
\text { received } \\
\text { prebiotic for } \\
6 \text { weeks }\end{array}$ & $\begin{array}{l}\text { Significantly lower scores of } \\
\text { GI symptoms, including } \\
\text { abdominal pain were } \\
\text { reported for the group with } \\
\text { exclusion diet }\end{array}$ \\
\hline Kang et al. (2017) & $\begin{array}{l}\text { To evaluate the impact of } \\
\text { microbiota transfer therapy } \\
\text { on GI and ASD symptoms }\end{array}$ & $N=18$ & $\begin{array}{l}7-17 \\
\text { years }\end{array}$ & $\begin{array}{l}\text { The gastrointestinal } \\
\text { symptom rating scale }\end{array}$ & $\begin{array}{l}\text { 10-week } \\
\text { microbiota } \\
\text { transfer } \\
\text { therapy } \\
\text { (MTT) and } \\
\text { 8-week } \\
\text { follow-up } \\
\text { observation } \\
\text { period }\end{array}$ & $\begin{array}{l}80 \% \text { reduction in GI } \\
\text { symptoms at the end of the } \\
\text { treatment }\end{array}$ \\
\hline $\begin{array}{l}\text { Mannion and Leader } \\
\text { (2016) }\end{array}$ & $\begin{array}{l}\text { To investigate the change in the } \\
\text { comorbid symptoms and } \\
\text { predictors of sleep problems } \\
\text { at a 2-year follow-up } \\
\text { timepoint }\end{array}$ & $N=56$ & $\begin{array}{l}5-19 \\
\text { years }\end{array}$ & $\begin{array}{l}\text { GI Symptom Inventory } \\
\text { Questionnaire (Autism } \\
\text { Treatment Network, } \\
\text { 2005) }\end{array}$ & N/A & $\begin{array}{l}73.2 \% \text { of participants } \\
\text { presented with at least one } \\
\text { GI problem and } 84.4 \% \text { of } \\
\text { GI symptoms persisted over } \\
\text { the 2-year follow-up, while } \\
\text { some participants devel- } \\
\text { oped novel GI symptoms }\end{array}$ \\
\hline Mazefsky et al. (2014) & $\begin{array}{l}\text { To investigate the association } \\
\text { between GI and emotional } \\
\text { and behavioral problems }\end{array}$ & $N=95$ & $\begin{array}{l}7-19 \\
\text { years }\end{array}$ & $\begin{array}{l}\text { GI Symptom Inventory } \\
\text { (Autism Treatment } \\
\text { Network, 2005) }\end{array}$ & N/A & $\begin{array}{l}61 \% \text { of participants reported at } \\
\text { least one GI problem and } \\
\text { participants with GI } \\
\text { problems had significantly } \\
\text { higher levels of affective } \\
\text { problems }\end{array}$ \\
\hline
\end{tabular}


Table 3 (continued)

\begin{tabular}{|c|c|c|c|c|c|c|}
\hline Study & Aim & $\begin{array}{l}\text { Sample } \\
\text { size }\end{array}$ & Age & $\begin{array}{l}\text { Abdominal pain } \\
\text { assessment tool }\end{array}$ & Intervention & Results \\
\hline & $\begin{array}{l}\text { To study the relationship } \\
\text { between GI symptoms and } \\
\text { anxiety, sensory } \\
\text { over-responsivity, and } \\
\text { chronic GI problems }\end{array}$ & & $\begin{array}{l}2-17 \\
\text { years }\end{array}$ & $\begin{array}{l}\text { GI Symptom Inventory } \\
\text { Questionnaire (Autism } \\
\text { Treatment Network, } \\
\text { 2005) }\end{array}$ & & $\begin{array}{l}24 \% \text { experienced at least one } \\
\text { type of chronic GI problem } \\
\text { and children with each type } \\
\text { of GI problem had } \\
\text { significantly higher rates of } \\
\text { both anxiety and sensory } \\
\text { over-responsivity }\end{array}$ \\
\hline Mazurek et al. (2014) & $\begin{array}{l}\text { To investigate abdominal pain } \\
\text { in children with ASD over a } \\
\text { 1-year period of time and } \\
\text { study it's relation to anxiety } \\
\text { and sensory over-- } \\
\text { responsivity }\end{array}$ & $N=255$ & $\begin{array}{l}2-17 \\
\text { years }\end{array}$ & $\begin{array}{l}\text { GI Symptom Inventory } \\
\text { Questionnaire (Autism } \\
\text { Treatment Network, } \\
\text { 2005) }\end{array}$ & N/A & $\begin{array}{l}25.8 \% \text { experienced chronic } \\
\text { abdominal pain at baseline } \\
\text { (BL), and } 86.7 \% \text { continued } \\
\text { to experience chronic } \\
\text { abdominal pain at } \\
\text { follow-up. Of those who } \\
\text { did not have chronic } \\
\text { abdominal pain at BL, } \\
23.8 \% \text { developed chronic } \\
\text { abdominal pain by } \\
\text { follow-up }\end{array}$ \\
\hline $\begin{array}{l}\text { Molloy \& } \\
\text { Manning-Courtney } \\
(2003)\end{array}$ & $\begin{array}{l}\text { To estimate the prevalence of } \\
\text { GI symptoms in children } \\
\text { with ASD }\end{array}$ & $N=137$ & $\begin{array}{l}\text { 24-96 } \\
\text { months }\end{array}$ & $\begin{array}{l}\text { GI symptoms recorded on } \\
\text { the medical history } \\
\text { abstracted from } \\
\text { hospital records }\end{array}$ & N/A & $\begin{array}{l}24 \% \text { of children had the } \\
\text { history of at least one } \\
\text { chronic GI problem }\end{array}$ \\
\hline Sandhu et al. (2009) & $\begin{array}{l}\text { To test whether ASD } \\
\text { symptoms are preceded by } \\
\text { enterocolitis }\end{array}$ & $N=12,984$ & $\begin{array}{l}4 \text { weeks } \\
\text { to } 4 \\
\text { years }\end{array}$ & $\begin{array}{l}\text { Questionnaire on stool } \\
\text { pattern developed by } \\
\text { the Avon Longitudinal } \\
\text { Study of Parents and } \\
\text { Children (ALSPAC) } \\
\text { (Steer et al., 2009) }\end{array}$ & N/A & $\begin{array}{l}\text { No major differences between } \\
\text { ASD and control group in } \\
\text { stool color, consistency, or } \\
\text { in frequency of diarrhea, } \\
\text { constipation, bloody stools, } \\
\text { or abdominal pain }\end{array}$ \\
\hline
\end{tabular}

pain; however, pain was still present. The results reported no significant improvement after the prebiotic intervention on GI symptoms.

Chandler et al. (2013) studied the difference between 44 children with ASD and 24 with SEN in relation GI symptoms and how varied their diet is. Limited diet was described as eating less than 10 different foods. Participants with ASD reported limited diet significantly more $(43.2 \%)$ than the SEN group (25\%). Although the ASD group had significantly higher scores on the GI symptoms scale compared to the SEN group, limited diet did not account for this difference. Gorrindo et al. (2012) also investigated the relationship between GI symptoms in 121 children with ASD and dietary habits. No significant correlation was found between GI symptoms and dietary patterns.

\section{Discussion}

The purpose of this paper was to systematically review existing literature on abdominal pain and ASD in children and adolescents in order to address the study's following research questions: (i) What prevalence rates are reported for abdominal pain and GI symptoms in children and adolescents with ASD? (ii) What are the factors and comorbidities associated with abdominal pain? and (iii) What are the available treatments options? Four key themes based on the research questions and the analysis of the content of the articles were identified from the 13 articles included in this review. Prevalence rates of abdominal pain and GI symptoms were initially discussed, followed by the associations of abdominal pain and emotional and behavioral problems, as well as comorbidities and lastly, treatment options were outlined.

Results from the reviewed articles were consistent in reporting significantly higher prevalence rates of GI symptoms in children and adolescents with ASD compared to TD peers. Results also found higher abdominal pain differences between the children and adolescents with ASD compared to TD controls. However, the range of percentages for GI symptoms and abdominal pain differed throughout the research; therefore, the prevalence is inconsistent. Inconsistencies in the prevalence rates can most likely be explained by the use of different assessment methods and tools in the studies. Molloy and Manning-Courtney (2003) used existing medical records to estimate the prevalence of abdominal pain, while Mazefsky et al. (2014) and eight other studies out of the 13 based their results on parent-report scales. Previous studies by Molloy and Manning-Courtney (2003) reported as little as 
$2.1 \%$ of the sample experiencing abdominal pain. On the contrary, Mannion and Leader (2016) reported much higher prevalence rates $(48.3 \%)$ for abdominal pain for the same. These inconsistencies have been further reported in studies using the same measures to assess GI symptoms (GI Symptoms Inventory Questionnaire, Autism Treatment Network, 2005), with the prevalence of abdominal pain ranging from 21.7 to $51 \%$. This finding highlights the need for the investigation of the reliability and validity of tools measuring GI symptoms as well as the need for further research on the prevalence of abdominal pain in children and adolescents with ASD. Interestingly, Gorrindo et al. (2012) assessed GI symptoms both with medical examination and parent-reported questionnaires and found $92.1 \%$ concordance between the results. This finding provides support for the use of parental report to assess GI symptoms in children and adolescents with ASD.

Both studies investigating the longitudinal prognosis of abdominal pain in children and adolescents with ASD found that abdominal pain persisted in extremely high percentages, $86.4 \%$ at the 1-year follow-up according to Mazurek et al. (2014) and 72.4\% was reported by Mannion and Leader (2016) at the 2-year follow-up. These results may be particularly important for practitioners, highlighting the need for better treatment options and continuous follow-up visits for patients with ASD and abdominal pain.

All articles studying the association between GI symptoms and emotional and behavioral problems in participants with ASD reported similar results that are also in line with previous research (Williams et al., 2015). Somatic problems were significantly higher according to both Mazefsky et al. (2014) and Fulceri et al. (2016) in the group with ASD and GI symptoms, compared to the one without. This is especially interesting, as the results stayed the same after zeroing out the effect of the GI specific items on the somatic problems subscale (Fulceri et al., 2016). This indicates that children with ASD and comorbid GI symptoms are also at risk of other somatic problems, such as idiopathic headache or aches and pains. This may add to the effect by which GI disturbances trigger affective and behavioral challenges due to the increased discomfort and may be worthwhile to investigate in future research.

Chaidez et al. (2014) found that abdominal pain and other GI symptoms are linked to irritability, social withdrawal, stereotypy, and hyperactivity, while Mazurek et al. (2014) reported a positive correlation between abdominal pain and anxiety. Both studies provide additional information on the kind of behavioral and emotional problems abdominal pain and GI disturbances may be associated with.

Results from this review also show that other comorbidities associated with children and adolescents with ASD and abdominal pain include language, social impairments (Gorrindo et al., 2012), and sleep problems (Mannion \& Leader, 2016). Although specific comorbidities associated with GI symptoms were not consistent between the studies in this review, there is evidence in support of GI concerns being related to affective and behavioral difficulties in the current literature. The question remains open, whether GI symptoms trigger emotional and behavioral disturbances, or whether a bi-directional relationship exists between them. More longitudinal research and further investigation of the relationship between these variables could add valuable information to the existing knowledge and inform practices as well.

Finally, a number of studies in this review suggest potential treatment options for GI symptoms for children with ASD. Kang et al. (2017) published promising findings on the use of MTT, eliminating $82 \%$ of GI symptoms with an 8 -week intervention that maintained well over time. Other research based on intestinal microbiota treatment (Grimaldi et al., 2018), however, found no favorable outcomes posttreatment. Furthermore, Gondalia et al. (2012) concluded that there is no significant difference between the gut bacteria of children with ASD and GI symptoms and their TD siblings without GI symptoms. MTT, successfully treating GI symptoms (Kang et al., 2017), is based on the hypothesis that children with ASD have an abnormal gut microbiome that affects both ASD symptom severity and GI symptoms. This finding is contradictory to the results of Gondalia et al. (2012) and Grimaldi et al. (2018) and warrants further investigation. Two studies from this review explored the potential mediating role of dietary habits in GI symptoms in children with ASD. Both Chandler et al. (2013) and Gorrindo et al. (2012) reported that food variety and the type of diet did not account for abdominal pain or other GI symptoms.

This study had some limitations. The definition for the variable abdominal pain in the inclusion criteria was a limitation in this study. It did not specify whether abdominal pain was experienced by children and adolescents with ASD with GI symptoms or abdominal pain experienced by children and adolescents with ASD as a stand-alone symptom. Future reviews may use a clearer refined definition for abdominal pain in their inclusion criteria to eradicate the subjective nature of this variable. Various studies included in this review relied on parental report as a measure of child pain. This may be acknowledged as a limitation as it may potentially account for some of the inconsistencies in prevalence rates of abdominal pain in children and adolescents with ASD. The current study could also be enhanced by evaluating the evidence-base for the reported treatment options.

In addition, the studies included in the review were significantly heterogeneous in relation to sample size, different methods, and the heterogeneity of results reported; therefore, it was not appropriate to conduct a meta-analysis. Participants in the studies ranged from 18 to 12,984 ; therefore, the sample sizes of the studies are extremely heterogeneous. Different papers used different methods to assess GI symptoms including parent report and using medical records. It is therefore unclear if GI measures across papers are necessarily 
measuring the same construct. Additionally, the prevalence of GI symptoms, inconsistencies relating to comorbidities associated with GI symptoms, and inconsistencies relating to treatment options made it impossible to combine the results of different studies in a meta-analysis.

Despite these limitations, important conclusions can be drawn for future research as well as implications for practice. There is strong evidence in support of the high prevalence of abdominal pain in children and adolescents with ASD compared to TD peers, and there are a number of adverse psychological and behavioral associations with this symptom. Future research could further examine the reliability of the findings reported in this review to ensure that this area is wellunderstood and can inform those working in clinical practice.

Further research is needed to investigate potential treatment options for children with ASD suffering from persistent abdominal pain, including research based on pharmacological as well as psychological theories (such as mindfulness, or relaxation). Research in the future needs to further explore the empirical support available for treatment options. Future research should also focus on other specific GI symptoms such as constipation, diarrhea, nausea, vomiting, bloating, and gastroesophageal reflux.

Funding Open Access funding provided by the IReL Consortium.

\section{Declarations}

Research Involving Human Participants and/or Animals This article does not contain any studies with human participants or animals performed by any of the authors.

Conflict of Interest All the authors of this article declare no competing interests.

Open Access This article is licensed under a Creative Commons Attribution 4.0 International License, which permits use, sharing, adaptation, distribution and reproduction in any medium or format, as long as you give appropriate credit to the original author(s) and the source, provide a link to the Creative Commons licence, and indicate if changes were made. The images or other third party material in this article are included in the article's Creative Commons licence, unless indicated otherwise in a credit line to the material. If material is not included in the article's Creative Commons licence and your intended use is not permitted by statutory regulation or exceeds the permitted use, you will need to obtain permission directly from the copyright holder. To view a copy of this licence, visit http://creativecommons.org/licenses/by/4.0/.

\section{References}

American Psychiatric Association. (2013). Diagnostic and statistical manual of mental disorders (5th ed.). https://doi.org/10.1176/appi. books. 9780890425596
Autism Treatment Network. (2005). GI Symptom Inventory Questionnaire, vers.3.0.New York, NY: Autism Speaks.

Buie, T. (2013). The relationship of autism and gluten. Clinical Therapeutics, 35(5), 578-583. https://doi.org/10.1016/j.clinthera. 2013.04.011.

Buie, T., Campbell, D. B., Fuchs, G. J., Furuta, G. T., Levy, J., VandeWater, J., Whitaker, A. H., Atkins, D., Bauman, M. L., Beaudet, A. L., Carr, E. G., Gershon, M. D., Hyman, S. L., Jirapinyo, P., Jyonouchi, H., Kooros, K., Kushak, R., Levitt, P., Levy, S. E., et al. (2010). Evaluation, diagnosis, and treatment of gastrointestinal disorders in individuals with ASDs: A Consensus Report. Pediatrics, 125(Supplement 1), S1-S18. https://doi.org/10. 1542/peds.2009-1878c.

Chaidez, V., Hansen, R. L., \& Hertz-Picciotto, I. (2014). Gastrointestinal problems in children with autism, developmental delays or typical development. Journal of Autism and Developmental Disorders, 44(5), 1117-1127. https://doi.org/10.1007/s10803-013-1973-x.

Chandler, S., Carcani-Rathwell, I., Charman, T., Pickles, A., Loucas, T., Meldrum, D., \& Baird, G. (2013). Parent-reported gastro-intestinal symptoms in children with autism spectrum disorders. Journal of Autism and Developmental Disorders, 43(12), 2737-2747. https:// doi.org/10.1007/s10803-013-1768-0.

Cvejic, R. C., Arnold, S. R. C., Foley, K. R., \& Trollor, J. N. (2018). Neuropsychiatric profile and psychotropic medication use in adults with autism spectrum disorder: Results from the Australian Longitudinal Study of Adults with Autism. BJPsych Open, 4(6), 461-466. https://doi.org/10.1192/bjo.2018.64.

Devlin, S., Healy, O., Leader, G., \& Reed, P. (2008). The analysis and treatment of problem behavior evoked by auditory stimulation. Research in Autism Spectrum Disorders, 2(4), 671-680. https:// doi.org/10.1016/j.rasd.2008.02.001.

Drossman, D. A. (2006). The functional gastrointestinal disorders and the Rome III process. Gastroenterology, 130(5), 1377-1390. https:// doi.org/10.1053/j.gastro.2006.03.008.

Erickson, C. A., Stigler, K. A., Corkins, M. R., Posey, D. J., Fitzgerald, J. F., \& Mcdougle, C. J. (2005). Gastrointestinal factors in autistic disorder: A critical review. Journal of Autism and Developmental Disorders, 35(6), 713-727. https://doi.org/10.1007/s10803-0050019-4.

Ferguson, B. J., Marler, S., Altstein, L. L., Lee, E. B., Mazurek, M. O., Mclaughlin, A., \& Beversdorf, D. Q. (2016). Associations between cytokines, endocrine stress response, and gastrointestinal symptoms in autism spectrum disorder. Brain, Behavior, and Immunity, 58, 57-62. https://doi.org/10.1016/j.bbi.2016.05.009.

Foody, C., James, J.E., \& Leader, G. (2014). Parenting stress, salivary biomarkers, and ambulatory blood pressure in mothers of children with Autism Spectrum Disorders. Research in Autism Spectrum Disorders, 8 (2), 99-110.

Frigerio, A., Cozzi, P., Pastore, V., Molteni, M., Borgatti, R., \& Montirosso, R. (2006). The evaluation of behavioral and emotional problems in a sample of Italian preschoolers using the Child Behavior Checklist and the Caregiver-Teacher Report Form. Infanzia e Adolescenza, 5(1), 24-32.

Fulceri, F., Morelli, M., Santocchi, E., Cena, H., Del Bianco, T., Narzisi, A., \& Muratori, F. (2016). Gastrointestinal symptoms and behavioral problems in preschoolers with autism spectrum disorder. Digestive and Liver Disease, 48(3), 248-254. https://doi.org/10. 1016/j.dld.2015.11.026.

Gondalia, S. V., Palombo, E. A., Knowles, S. R., Cox, S. B., Meyer, D., \& Austin, D. W. (2012). Molecular characterisation of gastrointestinal microbiota of children with autism (with and without gastrointestinal dysfunction) and their neurotypical siblings: GI microbiota of children with autism. Autism Research, 5(6), 419-427. https:// doi.org/10.1002/aur.1253.

Gorrindo, P., Williams, K. C., Lee, E. B., Walker, L. S., McGrew, S. G., \& Levitt, P. (2012). Gastrointestinal dysfunction in autism: Parental 
report, clinical evaluation, \& associated factors. Autism Research, 5(2), 101-108. https://doi.org/10.1002/aur.237.

Grimaldi, R., Gibson, G. R., Vulevic, J., Giallourou, N., Castro-Mejía, J. L., Hansen, L. H., \& Costabile, A. (2018). A prebiotic intervention study in children with autism spectrum disorders (ASDs). Microbiome, 6(1), 133. https://doi.org/10.1186/s40168-018-0523-3.

Kang, D.-W., Adams, J. B., Gregory, A. C., Borody, T., Chittick, L., Fasano, A., \& Krajmalnik-Brown, R. (2017). Microbiota transfer therapy alters gut ecosystem and improves gastrointestinal and autism symptoms: an open-label study. Microbiome, 5(1), 10. https:// doi.org/10.1186/s40168-016-0225-7.

Leader, G., \& Mannion, A. (2016a). Challenging behaviors. In J. L. Matson (Ed.), Handbook of Assessment and Diagnosis of Autism Spectrum Disorder (pp. 209-232). Cham: Springer International Publishing.

Leader, G., \& Mannion, A. (2016b). Gastrointestinal disorders. In J. L. Matson (Ed.), Comorbid Conditions Among Children with Autism Spectrum Disorders (pp. 257-281). Cham: Springer International Publishing.

Leader, G., Francis, K., Mannion, A., \& Chen, J. (2018). Toileting problems in children and adolescents with parent-reported diagnoses of autism spectrum disorder. Journal of Developmental and Physical Disabilities, 30(3), 307-327. https://doi.org/10.1007/s10882-0189587-z.

Leader, G., Tuohy, E., Chen, J. L., Mannion, A., \& Gilroy, S. P. (2020). Feeding problems, gastrointestinal symptoms, challenging behavior and sensory issues in children and adolescents with autism spectrum disorder. Journal of Autism and Developmental Disorders, 50, 1401-1410. https://doi.org/10.1007/s10803-019-04357-7.

Levy, S. E., Souders, M. C., Ittenbach, R. F., Giarelli, E., Mulberg, A. E., \& Pinto-Martin, J. A. (2007). Relationship of dietary intake to gastrointestinal symptoms in children with autistic spectrum disorders. Biological Psychiatry, 61(4), 492-497. https://doi.org/10.1016/j. biopsych.2006.07.013.

Maenner, M. J., Shaw, K. A., Baio, J., Washington, A., Patrick, M., DiRienzo, M., Christensen, D. L., Wiggins, L. D., Pettygrove, S., Andrews, J. G., Lopez, M., Hudson, A., Baroud, T., Schwenk, Y., White, T., Rosenberg, C. R., Lee, L.-C., Harrington, R. A., Huston, M., et al. (2020). Prevalence of autism spectrum disorder among children aged 8 years - Autism and developmental disabilities monitoring network, 11 sites, United States, 2016. MMWR. Surveillance Summaries, $(69,4), 1-12$. https://doi.org/10.15585/ mmwr.ss6904a1.

Mannion, A., \& Leader, G. (2013). An analysis of the predictors of comorbid psychopathology, gastrointestinal symptoms and epilepsy in children and adolescents with autism spectrum disorder. Research in Autism Spectrum Disorders, 7(12), 1663-1671. https://doi.org/ 10.1016/j.rasd.2013.10.002.

Mannion, A., \& Leader, G. (2014a). Attention-deficit/hyperactivity disorder $(\mathrm{AD} / \mathrm{HD})$ in autism spectrum disorder. Research in Autism Spectrum Disorders, 8(4), 432-439. https://doi.org/10.1016/j.rasd. 2013.12.02.

Mannion, A., \& Leader, G. (2014b). Epilepsy in autism spectrum disorder. Research in Autism Spectrum Disorders, 8(4), 354-361. https:// doi.org/10.1016/j.rasd.2013.12.012.

Mannion, A., \& Leader, G. (2016). An investigation of comorbid psychological disorders, sleep problems, gastrointestinal symptoms and epilepsy in children and adolescents with autism spectrum disorder: A two year follow-up. Research in Autism Spectrum Disorders, 22, 20-33. https://doi.org/10.1016/j.rasd.2015.11.002.

Mazefsky, C. A., Schreiber, D. R., Olino, T. M., \& Minshew, N. J. (2014). The association between emotional and behavioral problems and gastrointestinal symptoms among children with highfunctioning autism. Autism, 18(5), 493-501. https://doi.org/10. $1177 / 1362361313485164$.

Mazurek, M. O., Vasa, R. A., Kalb, L. G., Kanne, S. M., Rosenberg, D., Keefer, A., Murray, D. S., Freedman, B., \& Lowery, L. A. (2012). Anxiety, sensory over-responsivity, and gastrointestinal problems in children with autism spectrum disorders. Journal of Abnormal Child Psychology, 41(1), 165-176. https://doi.org/10.1007/s10802-0129668-x.

Mazurek, M. O., Keefer, A., Shui, A., \& Vasa, R. A. (2014). One-year course and predictors of abdominal pain in children with autism spectrum disorders: The role of anxiety and sensory overresponsivity. Research in Autism Spectrum Disorders, 8(11), 1508-1515. https://doi.org/10.1016/j.rasd.2014.07.018.

Moher, D., Liberati, A., Tetzlaff, J., \& Altman, D. G. (2010). Preferred reporting items for systematic reviews and meta-analyses: The PRISMA statement. International Journal of Surgery, 8(5), 336341. https://doi.org/10.1016/j.ijsu.2010.02.007.

Molloy, C. A., \& Manning-Courtney, P. (2003). Prevalence of chronic gastrointestinal symptoms in children with autism and autism spectrum disorders. Autism, 7(2), 165-171. https://doi.org/10.1177/ 1362361303007002004.

Mulloy, A., Lang, R., O’Reilly, M., Sigafoos, J., Lancioni, G., \& Rispoli, M. (2010). Gluten-free and casein-free diets in the treatment of autism spectrum disorders: a systematic review. Research in Autism Spectrum Disorders, 4(3), 328-339. https://doi.org/10.1016/j.rasd. 2009.10.008.

Neuhaus, E., Bernier, R. A., Tham, S. W., \& Webb, S. J. (2018). Gastrointestinal and psychiatric symptoms among children and adolescents with autism spectrum disorder. Frontiers in Psychiatry, 9, 515. https://doi.org/10.3389/fpsyt.2018.00515.

Newman, I., Leader, G., Chen, J. L., \& Mannion, A. (2015). An analysis of challenging behavior, comorbid psychopathology, and Attentiondeficit/hyperactivity disorder in Fragile X Syndrome. Research in Developmental Disabilities, 38, 7-17. https://doi.org/10.1016/j.ridd. 2014.11.003.

Sandhu, B., Steer, C., Golding, J., \& Emond, A. (2009). The early stool patterns of young children with ASD spectrum disorder. Archives of Disease in Childhood, 94(7), 497-500. https://doi.org/10.1136/adc. 2008.148866.

Schreck, K. A., Williams, K., \& Smith, A. F. (2004). A comparison of eating behaviors between children with and without autism. Journal of Autism and Developmental Disorders, 34(4), 433-438. https:// doi.org/10.1023/b:jadd.0000037419.78531.86.

Steer, C. D., Emond, A. M., Golding, J., \& Sandhu, B. (2009). The variation in stool patterns from 1 to 42 months: a population-based observational study. Archives of Disease in Childhood, 94(3), 231233. https://doi.org/10.1136/adc.2007.130849.

Tye, C., Runicles, A. K., Whitehouse, A. J. O., \& Alvares, G. A. (2019). Characterizing the interplay between autism spectrum disorder and comorbid medical conditions: An integrative review. Frontiers in Psychiatry, 9, 751. https://doi.org/10.3389/fpsyt.2018.00751.

Williams, S., Leader, G., Mannion, A., \& Chen, J. (2015). An investigation of anxiety in children and adolescents with autism spectrum disorder. Research in Autism Spectrum Disorders, 10, 30-40. https://doi.org/10.1016/j.rasd.2014.10.017.

Publisher's Note Springer Nature remains neutral with regard to jurisdictional claims in published maps and institutional affiliations. 